\title{
Practise what you preach: health behaviours and stress among non-consultant hospital doctors
}

\author{
Authors: Sinéad Feeney, ${ }^{\mathrm{A}}$ Kevin O'Brien, ${ }^{\mathrm{B}}$ Neasa O’Keeffe, ${ }^{\mathrm{C}}$ Anna Nic Con Iomaire, ${ }^{\mathrm{D}}$ Maureen E Kelly, ${ }^{\mathrm{E}}$ John \\ McCormack, ${ }^{F}$ Genevieve McGuire ${ }^{G}$ and David S Evans ${ }^{H}$
}

High rates of psychological distress, depression and suicide have been reported among doctors. Furthermore, many doctors do not access healthcare by conventional means. This study aimed to increase understanding regarding nonconsultant hospital doctors' (NCHDs') response to stress and barriers to accessing supports, and identify possible solutions. Medical manpower departments in $\mathbf{5 8}$ hospitals distributed a 25-item questionnaire to 4,074 NCHDs; we received 707 responses (response rate, $17.4 \%$ ). $60 \%$ of NCHDs were unable to take time off work when unwell; 'letting teammates down' (90.8\%) and 'difficulty covering call' ( $85.9 \%)$ were the leading reasons. 'Being too busy' (85\%), 'self-prescription' (66.6\%) and 'self-management' (53.1\%) were ranked highest in deterring NCHDs from visiting a general practitioner (GP). $22.9 \%$ of NCHDs would not attend a GP with anxiety or depression until they began to feel hopeless, helpless or suicidal. $12.2 \%$ would not seek help at all. $55 \%$ of respondents $(n=330)$ had to move away from partners or dependants due to work, negatively affecting the social supports of $82.9 \%$. Possible practical solutions were explored. NCHDS are a vulnerable population and have a particularly challenging lifestyle. Key recommendations include improved GP and counselling access for NCHDs, and addressing the culture of self-treatment and poor health behaviours through undergraduate and postgraduate education.

KEYWORDS: Burnout, doctors' health, stress, wellbeing, solutions

Authors: ${ }^{A} G P$ registrar, Western Training Programme in General Practice, Galway University Hospital, Galway, Ireland; ${ }^{B} G P$, graduate of the Western Training Programme in General Practice; ${ }^{C} \mathrm{GP}$ Registrar, Western Training Programme in General Practice; ${ }^{\mathrm{D}} \mathrm{GP}$, graduate of the Western Training Programme in General Practice; $\mathrm{E}_{\text {assistant director, Western Training Programme in General }}$ Practice; Fassistant director, Western Training Programme in General Practice; ${ }^{G}$ director, Western Training Programme in General Practice; ${ }^{\mathrm{H}}$ senior research officer, Department of Public Health, Health Service Executive West, Merlin Park Regional Hospital, Galway, Ireland

\section{Introduction}

Doctors may experience better physical health than the general population, but higher rates of mental illness, suicide, depression, compassion fatigue and substance misuse are widely described. ${ }^{1,2}$ In addition, workplace stress can lead to high rates of doctor burnout. ${ }^{2}$

Although the need to address doctors' health has been recognised, ${ }^{2-5}$ medical training internationally gives little emphasis to self-care. ${ }^{2}$ In Ireland, some support services are available for doctors, although these are limited. ${ }^{6}$

A key difficulty is the issue of unconventional access to health services. Studies have shown that doctors often engage in selfprescribing, self-referral, 'corridor consultations', denial and symptom minimisation. ${ }^{2,3,7}$ Many work through illness which can impact negatively on the care of their patients. ${ }^{2}$

Non-consultant hospital doctors (NCHDs) experience particular stressors associated with working in hospital jobs and being at an early stage of their careers. ${ }^{8}$ In Ireland, training requires NCHDs to frequently relocate. This, combined with health expenditure cutbacks, increased healthcare demand, non-compliance with the European Working Time Directive (EWTD) and increased public expectations, has led to difficult working conditions. ${ }^{8}$

This study aimed to identify the factors driving NCHD health behaviours, assess the impact of workplace stress on NCHDs and evaluate initiatives which may improve the health behaviours of this new generation of doctors. It also assessed their standard of self-care and preferred sources of support. There have been few studies ${ }^{1,9,10}$ worldwide focusing specifically on NCHD health behaviours and these were limited in terms of direct feedback from the doctors themselves.

\section{Methodology}

A review of the literature revealed that there were no validated instruments that specifically addressed the study objectives. However, elements from previous studies ${ }^{1,7,11,12}$ did contain similar components and these were adapted to facilitate comparisons. This resulted in the development of a 25 -item survey, which aimed to assess current health behaviours, the impact of work-related stress and coping strategies, sources of support, training in self-care and stress management, and invited feedback in terms of possible solutions and interventions to improve NCHD wellbeing. Response formats 
included Likert scales and dichotomous and nominal questions. Free text boxes accompanied 6 questions and respondents were invited to elaborate on responses. The survey was modified following a pilot study of directors and trainees on Ireland's Western Training Programme in General Practice (a four-year postgraduate training programme for general practitioners). Ethical approval was granted by the Irish College of General Practitioners' Ethics Committee.

The survey was administered online using Survey Monkey (www.surveymonkey.net). The human resource (HR) managers in all 62 public hospitals in the Republic of Ireland were contacted and 58 hospitals agreed to participate in the study. These hospitals forwarded an invitational email with a link to the online survey to all NCHDs currently in their employment $(\mathrm{n}=4,078)$. Follow-up contact was made to confirm distribution of the email. One week later a reminder email was sent to NCHDs. The link to the online survey was accessible between 6 and 29 November 2013 .

The quantitative data were analysed using SPSS v21 (Presidion, Dublin, Ireland). Pearson's chi-square with odds ratios (ORs) were utilised to determine the significance of emerging patterns. Qualitative text box responses were read and transcribed into Microsoft Word for Windows and thematically analysed by four authors (SF, KO'B, ANCI and N O'K). These thematic groupings were reported to give contextual background to the appropriate quantitative data. ${ }^{13}$

\section{Results}

\section{Sample demographics}

Responses were received from 707 NCHDs (response rate, $17.4 \%$ ) (Table 1). Compared to the overall population of NCHDs in Ireland, ${ }^{14}$ this study had an under-representation of NCHDs not in training (23.6 vs $37.4 \%$ ) and of those who graduated abroad (28.3 vs $48.9 \%$ ).

The proportions of male respondents both on training schemes ( 35.6 vs $47.4 \%$ ) and not on training schemes ( 57.3 vs $69.3 \%$ ) are also lower than national figures.

\section{Managing own health}

One-quarter $(24.8 \%, \mathrm{n}=482)$ of respondents reported performing well or very well at managing their own health, with $48.5 \%(n=319)$ being average and $26.8 \%(n=176)$ giving a poor or very poor rating. However, the majority $(61.3 \%, \mathrm{n}=$ 403) had been told by others that they neglected their health.

If unwell, $86.5 \%(n=532)$, stated that there were factors deterring them from attending a general practitioner (GP). The main factors that definitely or probably deterred respondents included being too busy $(86.0 \%, \mathrm{n}=461)$, GPs not being open when off work $(68.0 \%, \mathrm{n}=361)$, self-prescribing being easier $(67 \%, \mathrm{n}=357)$, and feeling that they 'should' be able to manage their health problems themselves $(54 \%, \mathrm{n}=288)$.

Since qualifying, $79 \%(\mathrm{n}=520)$ of respondents had at some stage felt too unwell to work. Of these, $60.2 \%(\mathrm{n}=313)$ were rarely or never able to take time off when unwell. Respondents were asked how likely ten different factors were to influence them to work through illness (Fig 1). Not wanting to let teammates down $(90.8 \%, \mathrm{n}=583)$ and difficulty obtaining cover $(85.9 \%, \mathrm{n}=553)$ were the highest rated factors. In

\section{Table 1. Profile of respondents.}

\begin{tabular}{lll} 
Parameter & $\mathbf{n}$ & $\%$ \\
Gender & & \\
Male & 286 & 40.5 \\
Female & 421 & 59.6 \\
Age, years & & \\
18-24 & 62 & 8.8 \\
$25-9$ & 279 & 39.5 \\
$30-4$ & 214 & 30.3 \\
$35-9$ & 96 & 13.6 \\
$40-9$ & 42 & 5.9 \\
$\geq 50$ & 14 & 2.0 \\
Years since graduation: & & \\
$<1$ & 91 & 12.9 \\
1-2 & 164 & 23.2 \\
$3-4$ & 126 & 17.8 \\
$>5$ & 326 & 46.1 \\
Nationality & & \\
Irish & & \\
Non-Irish & 485 & 68.6 \\
Education & 222 & 31.4 \\
\hline
\end{tabular}

$\begin{array}{lll}\text { Irish university } & 507 & 71.7\end{array}$

University abroad $\quad 200 \quad 28.3$

Training scheme

Emergency medicine $\quad 24 \quad 3.4$

$\begin{array}{lll}\text { Medical } & 137 & 19.4\end{array}$

$\begin{array}{lll}\text { Surgery } & 64 & 9.1\end{array}$

$\begin{array}{lll}\text { Anaesthetics } & 40 & 5.7\end{array}$

$\begin{array}{lll}\text { Psychiatry } & 24 & 3.4\end{array}$

$\begin{array}{lll}\text { Obstetrics and gynaecology } & 44 & 6.2\end{array}$

$\begin{array}{lll}\text { Paediatrics } & 60 & 8.5\end{array}$

$\begin{array}{lll}\text { General practice } & 77 & 10.9\end{array}$

Other training scheme not listed above $\quad 78 \quad 11.0$

Not currently or previously on a training scheme $\quad \begin{array}{lll}107 & 17.4\end{array}$ (internship complete)

\section{Education regarding self-care etc}

Undergraduate

Postgraduate

addition, not wanting to 'let patients down' emerged through analysis of free text: see quotes 1-3 in S1.

When asked at what stage they would seek help if they were suffering from symptoms of anxiety or depression, few (5.2\%, $n=29$ ) would seek help when their symptoms were mild. Over half would seek help if their symptoms were impacting on other people $(34.23 \%, \mathrm{n}=191)$ or on their work $(25.5 \%, \mathrm{n}=$ $142)$. Almost a quarter $(22.9 \%, \mathrm{n}=128)$ would only seek help 
Fig 1. Working through illness. Respondents rated how likely (definitely/probably/neutral/ probably not/definitely not) 11 factors were to influence them to work through illness. This graph displays combined percentages for those who rated the factor as definitely or probably being likely to influence them.

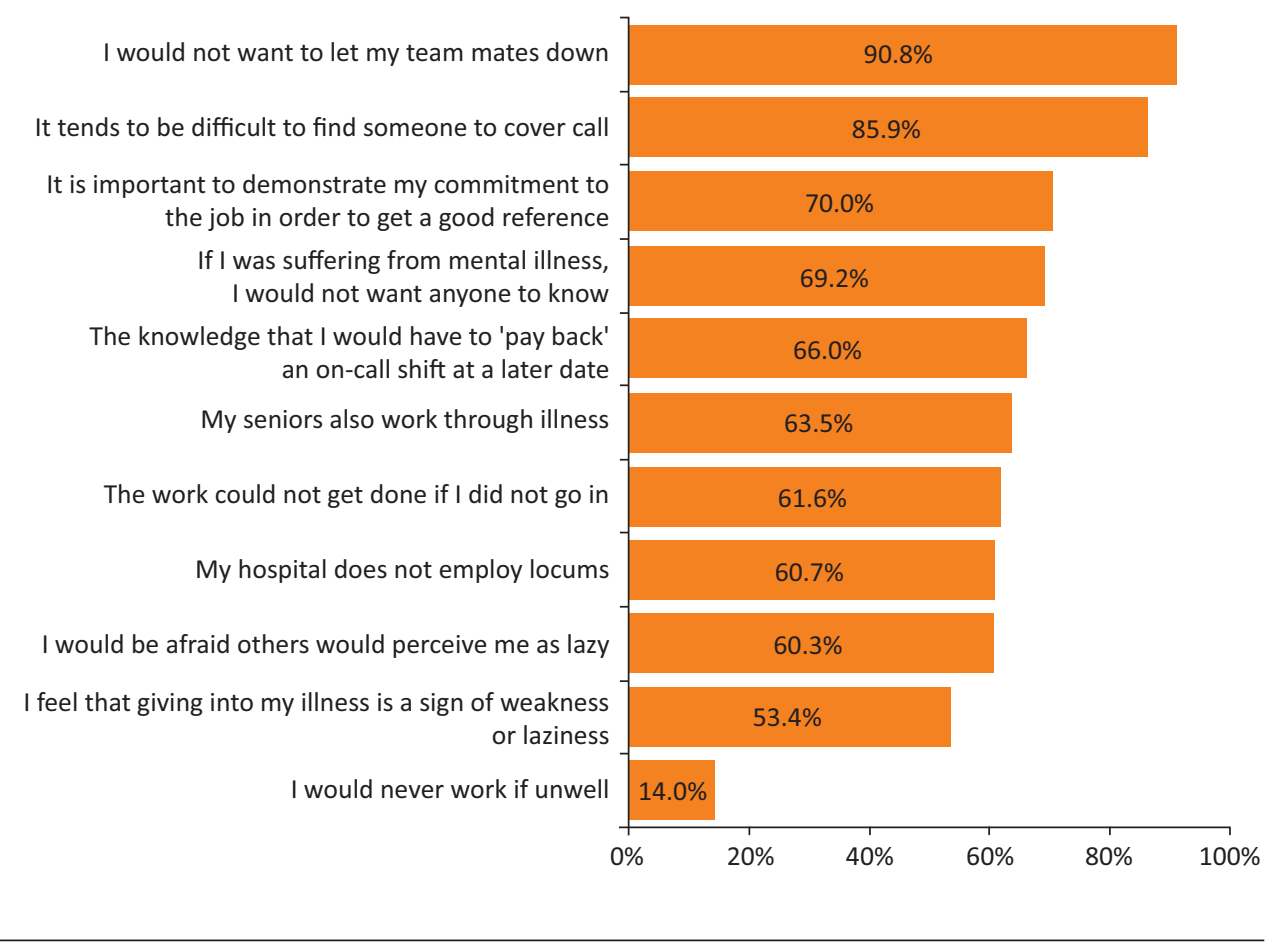

if they felt hopeless, helpless or suicidal. The remaining $12.2 \%$ $(\mathrm{n}=68)$ would not seek help.

\section{Work-related stress}

Respondents were asked to rate on a five-point scale how often (never - always) work-related stress (undefined) affected their performance or ability to enjoy life. Over one-quarter of respondents $(27.5 \%, \mathrm{n}=181)$ selected always or often, with $51.8 \%(\mathrm{n}=341)$ selecting sometimes. Respondents were given five statements and asked to select the one that best described how they react to work-related stress (Fig 2). Over half (55.2\%, $\mathrm{n}=363$ ) reported that stress occasionally caused them to become frustrated, tearful or to lose their temper, with a further $9.6 \%$ reporting that stress frequently affected them this way. A minority $(12.8 \%, \mathrm{n}=84)$ enjoyed feeling under pressure, with stress helping motivation. These were more likely to be male (OR, 1.565 ; $95 \%$ confidence interval (CI), 1.302-1.882; $<<0.001$ ), and on emergency medicine, surgical, or obstetrics and gynaecology training schemes (OR, 2.425; 95\% CI, 1.765-3.332; $\mathrm{p}<0.001$ ).

Since graduating, $29 \%(n=176)$ of respondents had worked in more than five locations, defined as requiring them to move house or commute for over one hour. Of these, $74.4 \%(n=131)$ believed that moving negatively affected their social support
Fig 2. Reacting to workrelated stress. Respondents were asked to select which of 5 statements best describe how they typically react to work-related stress.

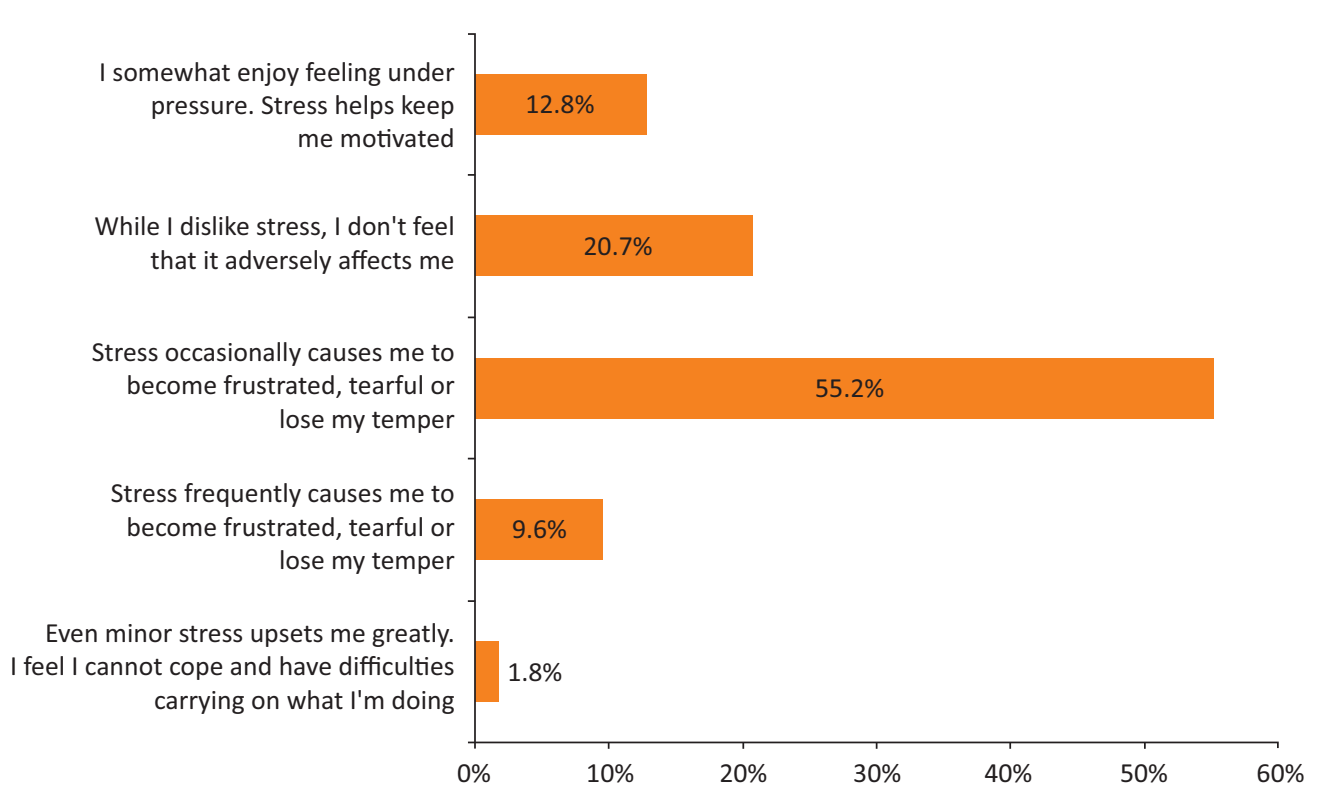


Table 2. Strategies for coping with stress. In total, 15 possible coping strategies were listed and respondents were asked to select how frequently they used them to cope with stress (always, often, sometimes, rarely, never, n/a). Strategies always or often employed are tabulated.

\section{Coping strategies*}

I watch a movie/TV programme $(n=632 ; m=243, f=389)$

I talk it out $(n=629 ; m=242, f=387)$

I watch a movie/TV programme $(n=632 ; m=243, f=389)$

I talk it out $(n=629 ; m=242, f=387)$

I go for a run/walk/other form of exercise $(n=634 ; m=246$, $f=388$ )

I listen to or play music $(n=627 ; m=243, f=383)$

I binge eat $(n=630 ; m=243, f=387)$

I am not aware of feeling stressed $(n=622 ; m=243, f=379)$

I withdraw into myself $(n=626 ; m=242, f=384)$

I take it out on others $(n=632 ; m=243, f=389)$

I pray, practise mindfulness or meditation $(n=628 ; m=243$, $f=385$ )

I drink more alcohol than usual $(n=627 ; m=242, f=385)$

I smoke more than usual $(n=626 ; m=243, f=383)$

I take prescription medications $(n=626 ; m=241, f=384)$

I take herbal remedies or over-the-counter medications $(n=627$; $m=243, f=384$ )

I write in my diary $(n=626 ; m=242, f=384)$

I take non-legal drugs $(n=624 ; m=241, f=383)$
Total respondents,

$\%$ (n)

$38.6(241)$

$37.7(237)$

$38.6(241)$

$37.7(237)$

$36.9(234)$

$34.6(217)$

$21.0(132)$

18.3 (114)

17.1 (107)

13.9 (88)

$13.4(84)$

12.0 (75)

7.3 (46)

2.7 (17)

$1.8(11)$

$1.3(8)$

$0.5(3)$

\section{$\%$ (n)}

41.6 (101)

26.9 (65)

41.6 (101)

26.9 (65)

33.7 (83)

$34.4(84)$

11.9 (29)

$23.0(56)$

$17.8(43)$

7.8 (19)

$15.6(38)$

15.7 (38)

10.7 (26)

$3.3(8)$

$0.4(n=1)$

$1.2(3)$

0.8 (2)
$\%$ (n)

36.0 (140)

44.4 (172)

36.0 (140)

$44.4(172)$

38.9 (151)

34.7 (133)

26.6 (103)

15.3 (58)

$16.7(64)$

17.7 (69)

$11.9(46)$

9.6 (37)

$5.2(20)$

$2.3 \%(9)$

2.6 (10)

1.3 (5)

0.3 (1)

*total number of respondents varied per coping strategy due to sample drop out. $m=$ male; $f=$ female

network. Over half $(55 \%, \mathrm{n}=330)$ had moved away from their partner or dependents due to work commitments, the majority $(82.9 \%, \mathrm{n}=274)$ of whom reported that this negatively or very negatively affected their ability to deal with stress. Analysis of free text responses revealed that while a few saw new locations as a 'fresh start', most highlighted the disruption to life, effect on family and relationships, isolation and the financial impact associated with multiple moves: see quote 4 (S1).

Respondents were given a list of 15 coping strategies and asked to state how often they used them to cope with stress (Table 2). Over one-fifth $(21 \%, \mathrm{n}=132)$ reported binge eating and these were more likely to be female (OR, 2.176, 95\% CI, 1.490-3.177; p $<0.001)$. 'Withdrawing into themselves' was reported by $17.1 \%$ $(\mathrm{n}=107)$. Females were more likely to 'talk it out' (OR, 1.634; 95\% CI 1.291-2.068; $\mathrm{p}<0.001)$ and to cope by taking it out on others (OR, 2.171; 95\% CI, 1.342-3.513; p<0.001). Analysis of the free text responses also identified positive thinking/ good intentions, engaging in hobbies and pastimes, sleeping and restricting eating as coping strategies. Lack of time to use positive coping strategies also emerged: see quotes 5 and 6 (S1).

\section{Solutions}

Potential interventions were identified from previous literature $e^{1,5,15,16}$ and from study team brainstorming.
Respondents were asked to rate them in terms of improving wellbeing, managing stress and accessing healthcare appropriately (Table 5). 8/11 interventions were rated as extremely or very helpful by the majority of respondents $(54.0-86.7 \%, \mathrm{n}=314-512)$. Analysis of free text responses identified the need to address the structure of training schemes (eg geographical clustering of training sites and adequate notice of moves, with reference to NCHD preference), hours and working conditions, inter-discipline understanding and respect, debriefing sessions and communication with management: see quotes 7 to 12 (S1).

\section{Discussion}

If doctors neglect their own health needs, it can have a detrimental impact both on their health and on patient care. $^{2}$ The use of poor health behaviours and a culture of self-treatment among NCHDs in Ireland are reported here, in agreement with previous studies. ${ }^{7,17,18}$ A strong sense of loyalty to colleagues and patients was identified, combined with a perceived lack of institutional support for taking sick leave. While loyalty and commitment are admirable traits, the negative impact on work performance and health appear to be overlooked. Ethical guidelines discourage self-treatment, ${ }^{19}$ however the practice of self-prescribing is known to be 
Table 3. Helpfulness of suggested interventions aimed at improving NCHD health behaviours as rated by respondents.

\begin{tabular}{|c|c|c|c|c|c|}
\hline Suggested intervention & $\begin{array}{l}\text { Extremely } \\
\text { helpful, } \\
\%(n)\end{array}$ & $\begin{array}{l}\text { Very } \\
\text { helpful, } \\
\%(n)\end{array}$ & $\begin{array}{l}\text { Moderately } \\
\text { helpful, } \\
\%(n)\end{array}$ & $\begin{array}{l}\text { Slightly } \\
\text { helpful, } \\
\%(n)\end{array}$ & $\begin{array}{l}\text { Not } \\
\text { helpful, } \\
\%(n)\end{array}$ \\
\hline $\begin{array}{l}\text { A relief system whereby a 'floating' SHO/registrar can fill gaps in } \\
\text { teams due to annual leave/sick leave }\end{array}$ & $65.3(385)$ & $21.5(127)$ & $8.8(52)$ & $3.2(19)$ & $1.2(7)$ \\
\hline A free, independent and confidential counselling service for NCHDs & $45.7(267)$ & $28.1(164)$ & $18.0(105)$ & $6.0(35)$ & $2.2(13)$ \\
\hline $\begin{array}{l}\text { Pleasant and spacious doctors' rest area where colleagues would feel } \\
\text { comfortable spending recreational time }\end{array}$ & $44.8(260)$ & $26.2(152)$ & $15.6(90)$ & $10.0(58)$ & $3.4(20)$ \\
\hline $\begin{array}{l}\text { An offer of a free GP consultation every one to two years for a } \\
\text { general check-up }\end{array}$ & $43.0(252)$ & $27.5(161)$ & $14.5(85)$ & $11.6(68)$ & $3.4(20)$ \\
\hline $\begin{array}{l}\text { A designated GP service for NCHDs within close proximity to the } \\
\text { hospital }\end{array}$ & $32.2(190)$ & $35.3(208)$ & $17.6(104)$ & $10.5(62)$ & $4.4(26)$ \\
\hline $\begin{array}{l}\text { A practitioner health programme - a confidential nationwide service } \\
\text { to which doctors who have significant health concerns can self-refer } \\
\text { or be referred }\end{array}$ & $26.4(155)$ & $38.7(227)$ & $23.8(140)$ & $7.4(43)$ & $3.7(22)$ \\
\hline $\begin{array}{l}\text { Postgraduate modules on the management of personal stress and } \\
\text { illness }\end{array}$ & $25.0(146)$ & $31.2(182)$ & $25.1(147)$ & $13.2(77)$ & $5.5(32)$ \\
\hline $\begin{array}{l}\text { Written information given at induction on any hospital or local sports } \\
\text { or social clubs in the area which may be of interest }\end{array}$ & $24.8(144)$ & $29.2(170)$ & $26.6(154)$ & $13.9(81)$ & $5.5(32)$ \\
\hline $\begin{array}{l}\text { An educational module for medical students dealing with personal } \\
\text { stress management and illness }\end{array}$ & $22.8(133)$ & $24.8(145)$ & 30.1 (176) & $15.1(88)$ & $7.2(42)$ \\
\hline $\begin{array}{l}\text { Written information given at induction on the availability of local } \\
\text { primary care services (GPs, counsellors etc) }\end{array}$ & 17.6 (103) & $29.8(175)$ & 27.2 (159) & $17.7(104)$ & 7.7 (45) \\
\hline $\begin{array}{l}\text { An information session delivered at induction, in relation to healthy } \\
\text { living and what to do if unwell }\end{array}$ & $15.3(90)$ & $17.6(103)$ & $31.2(183)$ & $24.8(146)$ & $11.1(65)$ \\
\hline
\end{tabular}

$\mathrm{GP}=$ general practitioner; NCHDs = non-consultant hospital doctors.

widespread. ${ }^{1,2,16}$ A 1993 UK study ${ }^{18}$ of 59 GPs and 64 hospital consultants found that 7 out of 10 would self-treat acute and chronic symptoms. Self-prescription was a key barrier to attending a GP in our study. A 2001 study $^{17}$ of 1,476 Norwegian physicians found that $80 \%$ had worked through an illness in the previous year. A study of 100 Irish GP trainees $(2007)^{7}$ identified that $65 \%$ had been ill and unable to take time off on at least one occasion since qualifying. Further consideration regarding how best to discourage the practice of self-treatment is warranted.

Worryingly, we found a marked reluctance among respondents to seek help even when suffering from severe psychological ill-health. This was also identified by Tyssen et al $(2004)^{9}$ in a survey of young Norwegian doctors $(\mathrm{n}=410)$, where one-third recognised a need for treatment for mental health problems but did not seek help.

The effects of workplace stress are reported. Similar trends are identified in previous studies. A UK study ${ }^{10}$ of junior medical officers (1987) found high levels of emotional distress with $28 \%$ $(\mathrm{n}=45)$ giving responses that indicated a depressive illness, and $6 \%(n=10)$ reporting suicidal thoughts. A systematic review of psychological ill health among health care staff ${ }^{16}$ found some similar workload issues impacting on health, namely long hours worked; work overload and its impact on personal lives; lack of control over work and poor social support. Disruption of support networks due to frequent moves was identified as a particular issue for our respondents. Support networks are important to help cope with stress. ${ }^{16,20}$ Although moving is a part of the training process, the number of moves should be restricted.

In terms of coping with stress, while some effective strategies were employed by our respondents, it is of concern that $1 / 5$ $(\mathrm{n}=132)$ binge eat (particularly females) and $17.1 \%(\mathrm{n}=$ 107) withdraw into themselves. Binge eating is associated with greater stress. ${ }^{21}$ Keeping stress internalised can lead to emotional exhaustion ${ }^{20,21}$ and may leave doctors ill-equipped to deal with the emotional demands of their job. Also of concern was that three respondents $(0.5 \%)$ reported using non-legal drugs to help them cope with stress. This may be a lower prevalence than their peers in the general population but raises significant legal, ethical and professional considerations. The impact on patient care and the association between substance abuse and suicide are key concerns. ${ }^{2}$

We identified very low rates of education in self-care among study participants. Medical councils and training bodies worldwide ${ }^{2,4,22}$ have acknowledged this gap in education and many are currently developing initiatives targeting the wellbeing of doctors and medical students. ${ }^{22}$

The need to improve working conditions and supports were dominant themes, as highlighted previously by Michie 
et al 2003. ${ }^{16}$ Many respondents suggested debriefing would be beneficial. Such sessions could help reduce burnout ${ }^{23}$ and facilitate learning, ${ }^{5}$ however there is conflicting evidence with regard to debriefing post trauma showing the potential to cause harm. ${ }^{23,24}$ Further studies are needed to assess the impact of debriefing specifically in the context of reducing stress in medical staff following a critical incident. It is promising that a national practitioner health programme, 'Physician health matters', has recently been launched in Ireland ${ }^{6}$ as recommended by the UK Department of Health ${ }^{4}$ among others.

The similarity of our key findings to other research from different countries and time periods highlights the overall lack of progress in terms of improving the health and wellbeing of doctors over the last 30 years.

\section{Strengths and limitations}

This is one of the largest $(\mathrm{n}=707)$ and most comprehensive studies of NCHD health behaviours conducted to date. It encompasses all specialties and those not in training, and uniquely focuses not only on barriers, but also solutions favoured by NCHDs. The use of qualitative free text responses provides insight into the key factors impacting on health and distress among NCHDs. The $17.4 \%$ response rate is relatively $\mathrm{low}^{3}$ and may have been improved with a second reminder email, an incentive, or direct access to respondents. FirthCozen $(1987)^{10}$ for example in a postal survey of emotional distress among junior house officers achieved a $72 \%$ response rate with a financial incentive. It must be acknowledged that online surveys are expected to have far lower response rates than other surveys. ${ }^{25,26}$ It is also worth noting that Markwell and Wainer ${ }^{1}$ in an online survey of the health and wellbeing of junior doctors achieved a similar response rate with direct access to respondents (22\%). Our response rate may also be an underestimate as it is based on totals from the Employment Census Report, which may not reflect the actual number of NCHDs sent the survey by Human Resource Managers (eg due to unfilled posts and incomplete email lists). This information was not accessible. Non-responder bias is an important factor to consider. Those personally affected by the issues raised may be more likely to respond to the survey. We have no information on non-responders. While the respondent population profile is broad, it under-represents male NCHDs, those that graduated from university abroad and those not on training schemes. These issues may negatively impact on the generalisability of this study. In responding to work-related stress questions, respondents were not given a definition of stress (to facilitate the elicitation of positive and negative beliefs). This limits comparisons with other studies on stress. 'Stress' is a term which is inherently subjective. In the UK the Health Service Executive defines stress as 'the adverse reaction people have to excessive pressures or other types of demand placed upon them'. ${ }^{27}$ The World Health Organization defines stress similarly and also highlights that the term 'stress' can be interpreted as 'pressure' or 'challenge'. ${ }^{28}$ Pressure which is regarded as acceptable to an individual is often positive, serving as a motivator and facilitating alertness, work and learning. ${ }^{28}$ Valid comparisons can only be made where the same definition of stress has been used.

\section{Implications for policy and practice}

Working conditions and supports available to NCHDs need to be significantly improved to help promote their wellbeing. Mechanisms must be developed to facilitate doctors attending GPs and other health services, in tandem with restrictions on self-prescribing. Doctors should receive comprehensive training in terms of their health and how to cope with stress. Full implementation of current initiatives under development ${ }^{6,29}$ is recommended. The structure of NCHD training should be examined to help minimise its negative impact on support networks. Implementing change will require ongoing monitoring and evaluation to ensure that positive outcomes are achieved. It is hoped that this will help to ensure long, healthy and satisfying careers within medicine for NCHDs.

\section{References}

1 Markwell AL, Wainer Z. The health and wellbeing of junior doctors: insights from a national survey. MJA 2009;191:441-4.

2 Tyssen R. Health problems and the use of health services among physicians: a review article with particular emphasis on Norwegian studies. Ind Health 2007;45:599-610.

3 Kay M, Mitchell G, Clavarino A, Doust J. Doctors as patients: a systematic review of doctors' health access and the barriers they experience. Br J Gen Pract 2008;58:501-8.

4 Department of Health. Invisible patients - report of the Working group on the health of health professionals. London: $\mathrm{DoH}, 2010$.

5 Firth-Cozens J. Interventions to improve physicians' well-being and patient care. Soc Sci Med 2001;52:215-22.

6 Mullen N. Funding secured for Physician Health Matters Programme. Irish Medical Times, 11 September 2015. Available online at www.imt.ie/news/latest-news/2015/09/funding-securedfor-programme.html [Accessed 13 November 2015].

7 Ní Úallacháin G. Attitudes towards self-health care: a survey of GP trainees. Ir Med J 2007;100:489-91.

8 McGowan Y, Morgan K. Through doctors' eyes: A qualitative study of hospital doctor perspectives on their working conditions. $\mathrm{Br} \mathrm{J}$ Health Psychol 2013;18:874-91.

9 Tyssen R, Vaglum P, Gronvold NT, Ekeberg O. Suicidal ideation among medical students and young phycisians: a nationwide and prospective study of prevalence and predictors. J Affect Disord 2001;64:69-79.

10 Firth Cozens J. Emotional distress in junior house officers. BMJ 1987;295:533-6.

11 Hu YY, Fix ML, Heyelone ND et al. Physicians' needs in coping with emotional stressors. Arch Surg 2012;147:212-17.

12 Chambers R, Wall D, Campbell I. Stresses, coping mechanisms and job satisfaction in general practitioner registrars. BJGP 1996;46:343-8.

13 Pope C, Mays N (eds). Qualitative research in health care. Oxford: Oxford Blackwell Publishing, 2006:69-70.

14 Irish Medical Council. Medical workforce intelligence report 2014: a report on the Annual Registration Retention Survey 2013. Dublin: IMC, 2014. Available online at www.medicalcouncil.ie/Newsand-Publications/Reports/Medical-Workforce-Report-2014.html [Accessed 9 November 2015].

15 Department of Health. Good doctors, safer patients: proposals to strengthen the system to assure and improve the performance of doctors and to protect the safety of patients. London: DoH, 2006.

16 Michie S, Williams S. Reducing work related psychological ill health and sickness absence: a systematic literature review. Occup Environ Med 2003;60:3-9. 
17 Rosvold EO, Bjertness E. Physicians who do not take sick leave: hazardous heroes? Scand J Public Health 2001;29:71-5.

18 Chambers RM. What should doctors do if they become sick? Fam Pract 1993;10:416-23.

19 Irish Medical Council. Guide to professional conduct and ethics for registered medical practitioners, 7th edition. Dublin: IMC, 2009. Available online at www.medicalcouncil.ie/News-and-Publications/ Publications/Professional-Conduct-Ethics/Guide-to-ProfessionalConduct-and-Behaviour-for-Registered-Medical-Practitioners-pdf. pdf [Accessed 9 November 2015].

20 Lemaire JB, Wallace JE. Not all coping strategies are created equal: a mixed methods study exploring physicians' self reported coping strategies. BMC Health Services Res 2010;10:208.

21 Groesz L, McCoy S, Carl J et al. What is eating you? Stress and the drive to eat. Appetite 2012;58:717-21.

22 Irish Medical Council. Health and the international experience. Dublin: IMC. Available online at www.medicalcouncil. ie/Information-for-Doctors/Health-Sub-Committee/Healthand-the-International-Experience.html [Accessed 9 November 2015].

23 Gunasingam N, Burns K, Edwards J, Dinh M, Walton M. Reducing stress and burnout in junior doctors: the impact of debriefing sessions. Postgrad Med J 2015;91:182-7.

24 van Emmerik AA, Kamphuis JH, Hulsbosch AM, Emmelkamp PM. Single session debriefing after psychological trauma: a metaanalysis. Lancet 2002;360:766-71.
25 Resnick RM. Comparison of postal and online surveys: cost, speed, response rates and reliability. Education Market Research and $\mathrm{MCH}$ Strategic Data, 2012. Available online at http://mchdata.com/ wp-content/uploads/2012/10/Comparison_of_Postal_and_Online_ Surveys.pdf [Accessed 9 November 2015].

26 Crouch S, Robinson P, Pitts M. A comparison of general practitioner response rates to electronic and postal surveys in the setting of the National STI Prevention Program. Aust N Z J Public Health 2011;35:187-9.

27 Health Service Executive (UK). What is stress? Liverpool: HSE. Available online at www.hse.gov.uk/stress/furtheradvice/whatisstress.htm [Accessed 9 November 2015].

28 Leka S, Griffiths A, Cox T. Work organisation and stress: systematic problem approaches for workers, employers and trade union representatives. Geneva: WHO, 2003.

29 Department of Health and Children. The report of the National Taskforce on Medical Staffing. Dublin: The Stationery Office, 2003.

Address for correspondence: Dr S Feeney, The Nurses Building, Galway University Hospital, Galway H91 YR71, Ireland.

Email: gpresearch2013@gmail.com 